\title{
GvHD Final Skin Score 2
}

National Cancer Institute

\section{Source}

National Cancer Institute. GvHD Final Skin Score 2. NCI Thesaurus. Code C131028.

Body surface area involvement is $19-50$ percent and there are superficial sclerotic features. 